UOT 678.674.742. 22.13.01+678.043

TRIQQLISIIDIL OLIQQEFIRI Və ED-20 QATRANI OSASINDA HIBRIDLəŞMIŞ EPOKSID KOMPOZISIYYALARININ ALINMASI VO TODQİQİ

\author{
${ }^{1}$ A.M. Mustafayev, ${ }^{1}$ R.İ. İsmayılova, ${ }^{1}$ N.Y. İşenko, \\ ${ }^{2}$ F.X. Şahgəldiyev, ${ }^{1}$ E.A. Ramazanov, ${ }^{1}$ B.O. Məmmədov \\ ${ }^{1}$ AMEA Polimer Materialları Institutu, Sumqayıt şəh. \\ AZ 5004, Sumqayıt ş., Səməd Vurğun küç., 124; e-mail: agamustafayev@mail.ru \\ ${ }^{2}$ Sumqaylt Dövlat Universiteti \\ AZ 5008, Sumqaylt ş., 43-cü mahalla
}

\begin{abstract}
Triqlisidil oliqoefiri və ED-20 epoksid qatranı qarışıqlarından nüfuzetmə polimer tor növünə malik hibridlaşmiş kompozisiyalar alınmış, onların fiziki-mexaniki va elektrik xassalori tədqiq olunmuşdur. Müəyyən edilmişdir ki, hibrid kompozisiyaların slxlı̆̆l, tor sıxlı̆̆l, fizikimexaniki xassalari, ayrt-ayrılıqda triqlisid oliqoefirinin va ED-20 qatranının eyni şəraitdo bərkidilməsindən alınan materialların analoji xassələrindən nəzərə çarpacaq dərəcədə yüksəkdir. Göstarilmişdir ki, ilkin komponentlarin nisbətini tənzim etmak yolu ila bu hibrid kompozisiyaların bərkidilməsindən alınan materialların asas istismar göstəricilarini maqsadyönlü dayişmək mümkündür.

Açar sözlor: epoksid qatranı, propantriol, 3-xlor-1,2-epoksipropan, polioksixlorpropilentriepoksid, polietilenpoliamin, kompozisiya, dielektrik, qarşılıql nüfuzetmə polimer toru, bərkimə
\end{abstract}

\title{
GíRiș
}

Müxtəlif aminlərin iştirakı ilə bərkidilən epoksid qatranları, onların funksional monomerelər va oliqomerlərlə modifikasiya üsulları, özündə eyni vaxtda həlledici və modifikator xassələrini cəmləşdirən yeni bərkidicilərin işlənib hazırlanması tədqiqatçıların diqqət mərkəzindədir. $\mathrm{Bu}$ sahədə aparılan tədqiqatları sonrakı inkişafinın perspektivli istiqamətlərindən biri, klassik epoksid torundan qarşılliqlı nüfuzetmə polimer tor növünə (QNT) və yarım qarşılıqlı nüfuzetmə polimer tor növünə (YQNT) yəni hibrid matrisli quruluşa keçməkdir [1,2].
Hibrid matrisli kompozisiyalar, danılmaz üstünlüklərə malikdir, lakin məlumdur ki, modifikatorlara da xüsusi tələblər irəli sürülür. Belə ki, onlar əsas (baza) qatranla uyuşmalı, mümkün qədər aşağı özlülüyə malik olmalı, ənənəvi bərkidicilərlə bərkimə reaksiyalarında iştirak edən güclü funksional qruplara malik olmalıdır. Təqdim olunan işin məqsədi TQO və ED-20 qatranı əsasında bərkidilmiş hibrid kompozisiyaların alınması və onların bir sıra fiziki-kimyəvi xassələrinin kompozisiyanın tərkibindən asılılığının dinamikasının öyrənilməsidir.

\section{TəCRÜBİ HİSSə}

Baza qatranı kimi tərkibində molekul kütləsi 400 və epoksid ədədi 21.6\% olan ED20 qatranından və bərkidici kimi PEPA-dan istifadə edilmişdir. Mərhələli polikondensasiya yolu ilə [3,4] saylı işdə verilmiş metodla 3xlor-1,2-epoksipropanın propantriolla qarş̧1ıqlı təsirindən sintez olunmuş triqlisidil oliqoefiri (TQO) 18-19\% epoksid adədinə malikdir və $19 \%$ xlor saxlayır. Hesablanmış miqdar ED-20 və TQO-nun su hamaminda
(323-333 K) tamamilə homogen sistem alınana qədər intensiv qarışdırılması, sonra isə sistemə PEPA bərkidicisinin daxil edilməsi ilə kompozisiya hazırlanmışdır. Komponentlərin tamamilə həll olmasindan sonra kompozisiyanı vakuum altında qazsızlaşdırılmış və sınaq nümunələri üçün lazım olan ftoroplast qəliblərə tökülmüşdür. Otaq temperaturunda 24 saat saxlanıldıqdan sonra kompozisiya 323 və $353 \mathrm{~K}$-də 6 saat, sonra isə $393 \mathrm{~K}$-də 12 saat 
müddətində mərhələli bərkidilmișdir. Kompozisiyanın bərkimə dərəcəsini Sokslet aparatında xırdalanmış nümunələrin asetonla 8 saat müddətində ekstraksiyası ilə təyin edilmişdir. Bərkimiş kompozisiyaların sıxlığı isə $20^{\circ} \mathrm{C}$-də distillə suyunda silindrik nümunələri Vestfal-Mor tərəzisində hidrostatik çəkməklə müəyyən edilmişdir. Teplofiziki və teplomexaniki ölçmələri nümunələrin dövri olaraq yüklənməsi ilə diametri $8 \mathrm{~mm}$ və hündürlüyü $10 \mathrm{~mm} 6 \mathrm{kq}$ yük altında olan nümunələrdə $1.2^{0}$ dəq. sabit sürətlə temperatur artırılması rejimində Qeplerin modernləşdirilmiş konsistometrində aparılmışdır. Fiziki-mexaniki sınaqlar isə otaq temperaturunda mövcud standartların tələblərinə cavab verən laboratoriya sinaq maşınlarında həyata keçirilmişdir.

Dielektrik ölçmələr alüminium (folqa) elektrodlarla sürtülmüş (çəkilmiş) disk nümunələrində üçelektrodlu sxemə əsasən E6-13 teraommetrdə və $1 \mathrm{kHs}$ tezlikdə rəqəmsal tutum ölçü cihazında aparılmışdır.

\section{NOTİCəLəR Və ONLARIN MÜZAKİRəSI}

Eyni zamanda modifikasiya və bərkimədə iştirak edə bilən funksional qruplar arasında konformasıyalı çevik fraqmentlərin kifayət edəcək məsafədə olmasının mümkünlüyü əsas şərtlərdən biridir. Komponentlərin termodinamiki uyuşması baza qatranı və modifikatorun miqdarı ilə müqayisə edilə biləcək qarışıq kompozisiyalara keçməyə imkan yaradır ki, bu da formalaşan QNT quruluşu parametrlərinə əhəmiyyətli dərəcədə təsir etməyə, hibrid əlaqələndiricisinin fizikikimyəvi, mexaniki və fiziki teplofiziki<smiles>ClCC(COCC(COCC(CCl)OCC1CO1)OCC(CCl)OCC1CO1)OCC1CO1</smiles>

Aparılmış ilkin eksperimentlərin nəticələrinə həm də istifadə edilən qatranın epoksid ədədinin qiymətinə görə bərkidicinin (Polietilenpoliamin - PEPA) optimal qatılığ 15\% kütlə seçilmişdir. Qeyd etmək lazımdır ki, ED-20 qatranı ilə müqayisədə TQO qatranı aşağ1 özlülüyə malikdir. Eyni zamanda reaksiya şəraitindən asılı olaraq sintez edilən TQO qatranının epoksid ədədini müəyyən intervalda dəyişmək mümkündür. Tədqiq olunan qatranların amin bərkidicilərlə bərkimə prosesinin intensivliyinə görə müəyyənləşdirilmişdir ki, ED-20 qatranı ilə müqayisədə TQO qatranı aşağı sürətlə bərkiyir və uyğun olaraq onun əsasında hazırlanmış kompozisiyaların yaşama müddəti böyükdür.

Eksperimentlərin həyata keçirilməsində epoksid ədədi 18-19\% kütlə olan TQO qatranı edilmişdir. xassələrinin geniş intervalda dəyişdirilməsinə imkan verir. Göstərilən tələblərə isə, üçflüorlu borun $\left(\mathrm{BF}_{3}\right)$ iştirak1 ilə propantriolun 3-xlor1,2-epoksipropanla qarşılıqlı təsirindən alınan vo zoncirin sonunda triepoksid tsikli olan polioksixlorpropilentriepoksid oliqoefiri (TQO) tamamilə cavab verir. Aşağıda göstərilən quruluşa malik oliqoefirin preparativ sintezi vo prosesin kinetik qanunauyğunluqları ədəbiyyatda [3] saylı işdə verilmişdir.

istifadə olunmuş və kompozisiyada hər bir komponentin miqdarının 0-100\% kütlə, intervalında dəyişməsilə ED-20 və TQO qatranlarının binar qarışıqları tədqiq

Qəbul olunmuş təsnifata əsasən bu kompozisiyalar, bir mərhələdə eyni vaxtda əmələ gələn QNT- quruluşuna aid edilirlər. Baxmayaraq ki, TQO qatranı ED-20 qatranına nisbətən bir qədər aşağı surətdə bərkiyir. Lakin quruluş əmələ gətirmə prosesinin hər ikisi praktiki olaraq zamana görə ayrılmır və paralel baş verir. Yəqin ki, belə oxşar sistemlərdə ED-20 vo TQO qatranlarının komponentlərindən başqa müəyyən miqdarda blok və calaq birgəpolimerlərin alınması arzu olunan kimi qiymətləndirilə bilər. ED-20 və TQO qatranlarının uyuşması yüksəkdir və 
onların qatılıqlarının bütün nisbətlərində şəffaf bircinsli qarışıqlar yaranır. Lakin quruluş əmələ gətirmə prosesində ilkin qatranların uyuşma şəraitinin pozulması baș verə bilər və bu zaman bərkiyən sistem heterofazalı hala keçə bilər. Belə hallarda calaq birgəpolimerlərin əmələ gəlməsi sistemin homogenliyinin saxlanılmasını təmin edən bir vasitəçi rolu oynayır. Oxşar hallar digər tədqiqatçılar tərəfindən də qeydə alınmışdır [5]. Bizim müşahidələrə görə öyrənilən binar sistemlər bərkiyəndən sonra yüksək homogenliyi və şəffaflığı saxlayırlar.

Tədqiq edilən kompozisiyaların quruluş əmələgətirmə prosesinin tipik kinetik əyrisi (gel-fraksiya miqdarının bərkimə vaxtından asılı1ığı) şəkil 1-də təqdim olunmuşdur.

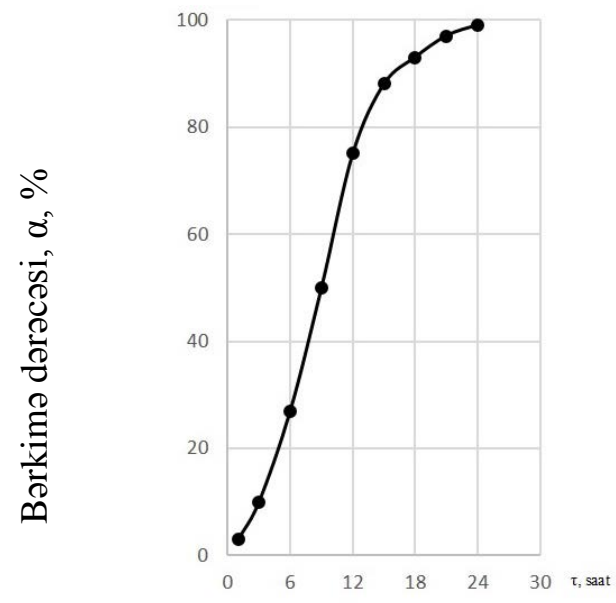

Şəkil 1. ED-20/TQO (50/50) kompozisiyanın quruluş əmələgətirmə prosesinin kinetik әyrisi. (T-353 K)

Bütün bərkidilmiş kompozisiyalarda gelfraksiyanın miqdarı 98\%-dən az olmamışdır. Müxtəlif tərkibli bərkidilmiş kompozisiyaların sıxlığının ölçülməsi (Şək.2) göstərir ki, bərkidilmiş TQO qatranı ED-20 qatranı ilə müqayisədə nəzərə çarpacaq yüksək sıxlığa

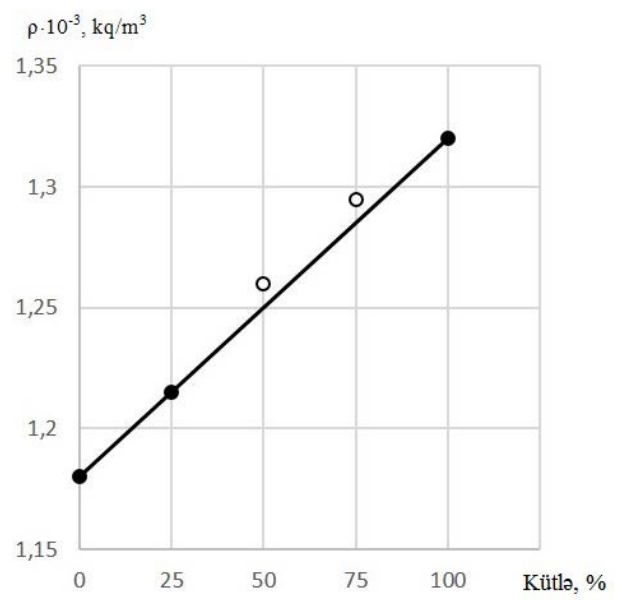

Şəkil 2. ED-20/TQO (50/50) kompozisiyalarında TQO-nun miqdarından sıxlığın asılılı̆̆1.

Ehtimal etmək olar ki, quruluş əmələgətirmə prosesində hər bir qatran öz fərdililiyini kifayət dərəcədə saxlayır; bu da qarışıqda sıxlıqların additivliyini təmin edir. malikdir. Kompozisiyada TQO qatranının kütlə payını artırdıqca, tərkibdən asılı olaraq sıxlıq monoton artır və bu zaman additiv qiymətlərdən nəzərə çarpacaq dərəcədə fərqlənən kənara çıxmalar baş vermir. 
ikiölçülü tikilməyə daha meylli olması ilə əlaqələndirmək olar.

Müxtəlif tərkibli kompozisiyaların bərkidildikdən sonra termomexaniki əyriləri şək.3-də

verilmişdir.

kompozisiyaların xarakteristikası nisbətən yüksək gərginlikdə (1.2 $\mathrm{MPa})$ müəyyən edilmişdir.

\section{目, $\mathrm{mm}$}

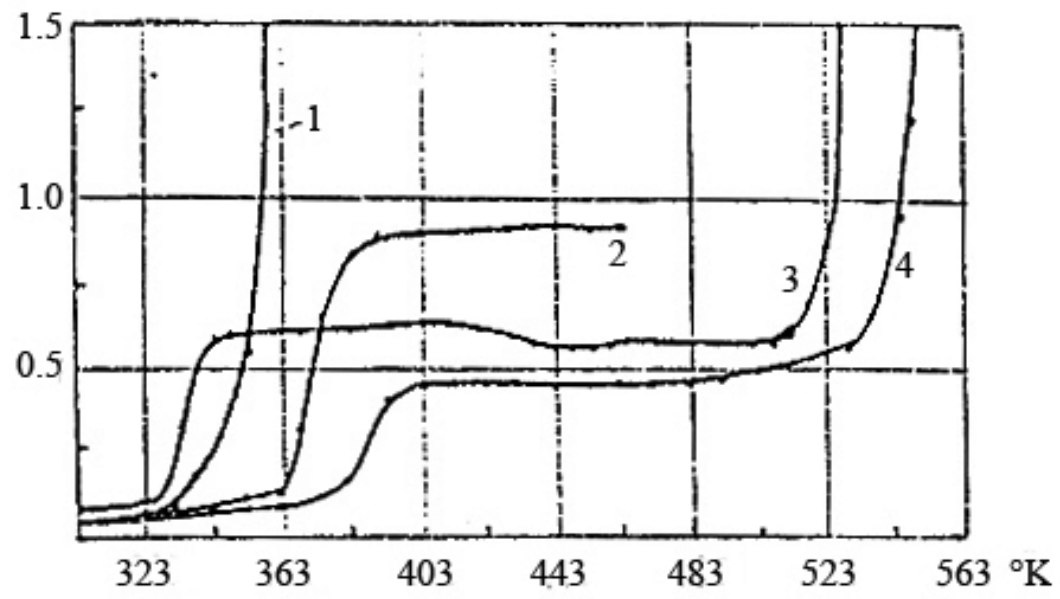

Şəkil 3. PEPA ilə bərkidilmiş ED/TQO kompozisiyası və epoksid qatranın termomexaniki әyriləri. 1-ED-20, 2-ED/TQO (75/25), 3-TQO-qatran1, 4- ED/ TQO (50/50).

Şəkildən göründüyü kimi 323 K-də modulunun kəmiyyəti 523 K-nə çatana qədər bərkidilmiş TQO qatranı yüksək elastiklik praktiki olaraq dəyişmir, bundan sonra isə halına keçir və həm də, bu sahədə elastiklik destruktiv axıcılıq müşahidə olunur.

Cədvəl 1. PEPA-ilə bərkidilmiş ED-20/TQO qatranının fiziki-mexaniki və dielektrik göstəriciləri

\begin{tabular}{|c|c|c|c|c|c|}
\hline \multirow{2}{*}{ Göstəricilər } & \multicolumn{4}{|c|}{ Uyğun olaraq ED-20/TQO müvafiq nisbətləri } \\
\cline { 2 - 6 } & $\begin{array}{c}0 / 100 \\
\text { ED-20/TQO }\end{array}$ & $25 / 75$ & $50 / 50$ & $75 / 25$ & $\begin{array}{c}100 / 0 \\
\text { ED-20/TQO }\end{array}$ \\
\hline $\begin{array}{c}\text { Gərilmədə möhkəmlik } \\
\text { həddi, MPa }\end{array}$ & 22 & 34 & 87 & 72 & 48 \\
\hline Nisbi uzanma, \% & 40 & 44 & 60 & 36 & 5.4 \\
\hline Zərbə özlülüyü, kC/m ${ }^{2}$ & - & 32 & 66 & 22 & 17 \\
\hline Bərklik NV, MPa & 48 & 69 & 99 & 105 & 126 \\
\hline $\begin{array}{c}\text { Dielektrik xassələri: } \\
\varepsilon\end{array}$ & 5.6 & 5.1 & 4.4 & 4.0 & 3.8 \\
$\begin{array}{c}\text { Dielektrik·itgi } \\
\text { bucağının tangensi } \\
\rho_{\mathrm{v}}(\text { Om·sm) } \\
\rho_{\mathrm{s}}(\text { Om) }\end{array}$ & 0.077 & 0.052 & 0.037 & 0.027 & 0.022 \\
\hline $\begin{array}{c}\text { Elektrik möhkəmliyi, } \\
\mathrm{kV} / \mathrm{mm}\end{array}$ & $7 \cdot 10^{13}$ & $4.8 \cdot 10^{13}$ & $1.6 \cdot 10^{14}$ & $1.2 \cdot 10^{14}$ & $1.2 \cdot 10^{14}$ \\
& 16 & $7 \cdot 10^{13}$ & $6 \cdot 10^{14}$ & $6 \cdot 10^{14}$ & $5 \cdot 10^{14}$ \\
\hline
\end{tabular}

Qarşılıqlı nüfuzetmə torunda qovşaqların oliqomerin ayrı-ayrılıqda əmələ gətirdiyi qatılığı ED-20/TQO kompozisiyasında komponentlərin miqdarının 50/50 nisbətində maksimuma çatır və bu kəmiyyət hər bir ilkin torvarı quruluşda olandan yüksəkdir. Bir sıra müəlliflərin fikrinə görə, bu əsasən iki torun qarşılıqlı nüfuz etməsi zamanı mexaniki 
ilgilərin miqdarının artması ilə əlaqədardır. Yüksək tor çıxımına malik daha mükəmməl quruluşun yaranması isə şüşəvari hala keçid temperaturunun $371 \mathrm{~K}$-nədək artmasına səbəb olur, 50/50 tərkibli kompozisiyalarda bu kəmiyyət ayrı-ayrılıqda götürülən hər bir komponentdən alınan materiallarla müqayisədə $30-35^{0}$ yüksəkdir.

Ilkin komponentlərin sistemdəki nisbətləri QNT-nin mexanık1 xassələrinə də kəskin şəkildə təsir göstərir. Cədvəl 1-dən göründüyü kimi, möhkəmlik, deformasiya və zərbə özlülüyünün maksimum göstəriciləri TQO/ED-20 = 50/50 kompozisiyalarda

Epoksid kompozisiyaları yüksək istismar göstəricilərinə malik ənənəvi dielektriklərdir [6-9]. Codvəl 1-də təqdim olunan dielektrik xüsusiyyətləri birmənalı olaraq sübut edir ki, alınan QNT-lərdə yüksək dielektrik xassələri saxlanilır, optimal tərkibdə isə kompozisiyaların dielektrik möhkəmliyi ayr1ayrılıqda hər bir komponentin dielektrik möhkəmliyindən yüksəkdir.

Beləliklə ED-20 və TQO homopolimerlərindən QNT tipində hibrid müşahidə olunur, hansı ki, bu kəmiyyətlərin qiymətləri həm TQO, həm də ED-20 əsasında alınan materiallar üçün də nəzərə çarpacaq qədər yüksəkdi. Müşahidə olunan bu fakt tikilmələrin yüksək sıxlığı və müxtəlif cinsli zəcirlərin qarşılıqlı nüfuzetməsi ilə əlaqələndirilə bilər.

Kompozisiya tərkibinin dəyişməsilə sıxlığının və eyni zamanda bərkliyin də monoton dəyişməsini isə kompozisiyada yüksək homogenlik dərəcəsi və formalaşan matris quruluşunda hər bir komponentin daha nizamlanmış qaydada iştirakı da izah edilə bilər.

binar qarışıqlara keçid epoksid kompozisiyalarının yüksək dielektrik xassələrini saxlamaqla onların əsas istismar göstəricilərini yüksəltməyə imkan verir. Alınmış QNT-lərin xassələri əhəmiyyətli dərəcədə tərkibdən asılıdır, lakin qarışıqda komponentlərin yaxşı uyuşması kompozisiyalarda komponentlərin nisbətini tənzimləmək yolu ilə bu göstəriciləri geniş intervalda dəyişdirilməsinə imkan yaradır.

\section{REFERENCES}

1. Polymer mixtures / Edited by Paul D. and Newman S. Moscow: Mir Publ., 1981, vol. 2, p. 6.

2. Physics-chemistry of multicomponent polymer systems / Edited by Lipatov Yu.S. Kiyev: Naukova dumka, 1986, vol. 2, pp. 68-137.

3. Mustafayev A.M., Alekperov N.A., Murshudova S.Dzh. Some peculiarities of synthesis and properties of chlorine-containing oligoester on the basis of propantriol and 3-chloro1,2-epoxypripane. Azerb.Chem.J. 2006, no. 2, pp. 33-37.

4. Mustafayev A.M., Ismailova R.I., Guseinov I.A., Ramazanov E.A., Karayeva A.M., Suleymanov G.I. Synthesis and properties of epoxyacrylate oligoesters on the basis of propantriol. Azerb. Chem.J. 2015, no. 1, pp. 44-49.

5. Alekseeva T.T. Dependence of the microphase structure of interpenetrating polymer networks on the nature of the combining additive. Vysokomolek.soyed - Polymer Science. A. 1999, vol. 41, no. 9, pp. 1510-1512. (In Russian).

6. Sazhin B.I. Electrical properties of polymers. Leningrad: Khimiya Publ., 1986, 224p.

7. Lusheykin G.A. Methods of investigation of electrical properties of polymers. Moscow: Khimiya Publ., 1980, 160p.

8. Chukalin A.V., Bogdanova L.M., Elizarova T.L. and et al. Study of electrical conductivity of hardening epoxy amine model system. Vysokomolek.soyed - Polymer Science.A. 2000, vol. 42, no.7, pp. 1228-1237. (In Russian).

9. Chernov I.A., Deberdeev T.R., Novikov G.F., Garipov R.M., Irzhak V.I. Dielectrical investigations of low temperature hardening of epoxide resin ED-20. Plast.Massy.Plastics. 2003, no. 8, p. 5. (In Russian). 


\title{
PREPARATION AND INVESTIGATION OF HYBRIDE EPOXIDE COMPOSITIONS ON THE BASIS OF TRIGLYCIDYL OLIGOESTER AND EPOXIDE RESIN ED-20
}

\author{
A.M. Mustafayev, R.I. Ismailova, N.Ya. Ishenko, F.Kh. Shakhgediyev, \\ E.A. Ramazanov, B.A. Mamedov \\ ${ }^{1}$ Institute of Polymer Materials National Academy of Sciences of Azerbaijan \\ 124, S.Vurgun str., AZ5004, Sumgait, e-mail: agamustafayev@mail.ru \\ ${ }^{2}$ Sumgait State University \\ quar.43 AZ5008, Sumgait
}

Based on the synthesized triglycidyl oligoether and epoxy resin ED-20, hybrid matrix compositions were obtained, their physicomechanical and dielectric properties were investigated It found that the density and physical-mechanical properties of hybride compositions were considerably higher than analogous properties of the hardened materials on the basis of triglycidyl esters and ED-20 taken separately. It revealed that a transition from homopolymers on the basis of ED-20 and triglycidyl oligoester to hybride binary mixtures of interpenetrating net allows to essentially improve the properties of epoxide compositions in terms of conservation of dielectrical indices.

Keywords: epoxide resin, propantriol, 3-chloro-1,2-epoxypropane, polyepoxypropylenetriepoxide, polyethylene polyamine, composition, dielectric, polymer interpenetrating nets, hardener

\section{ПОЛУЧЕНИЕ И ИССЛЕДОВАНИЕ ГИБРИДНЫХ ЭПОКСИДНЫХ КОМПОЗИЦИЙ НА ОСНОВЕ ТРИГЛИЦИДИЛОВОГО ОЛИГОЭФИРА И СМОЛЫ ЭД-20}

\author{
А.М. Мустафаев, Р.И. Исмаилова, Н.Я. Ищенко, Ф.Х. Нахгелдиев, \\ Э.А. Рамазанов, Б.А. Мамедов \\ ${ }^{1}$ Институт Полимерных Материалов Наџиональной АН Азербайджана \\ AZ 5004, г. Сумгайыт., ул. Самед Вургуна, 124; e-mail: agaтustafayev@mail.ru \\ ${ }^{2}$ Сумгайытский Государственный Университет \\ AZ 5008, г. Сумгайыт., 43-й квартал
}

На основе синтезированного триглищидилового олигоэфира и эпоксидной смольг ЭД-20 получены гибридные матричные композичии, исследованы их физико-механические и диэлектрические свойства. Установлено, что плотность и физико-механические свойства гибридных композиций значительно выше, чем аналогичные свойства отвержденных материалов на основе триглицидиловых эфиров и ЭД-20 в отдельности. Показано, что переход от гомополимеров на основе ЭД-20 и триглицидилового олигоэфира к гибридным бинарным смесям типа взаимопроникающей сетки позволяет значительно улучшить свойства эпоксидных композищий при сохранении высоких диэлектрических показателей.

Ключевые слова: эпоксидная смола, пропантриол, 3-хлор-1,2-эпоксипропан, полиоксихлорпропилентриэпоксид, полиэтиленполиамин, композиция, диэлектрик, полимерные взаиопроникающие сетки, отвердитель. 